\title{
الحماية الجنائية للمستهلك من الإثهار الإحتيالي
}

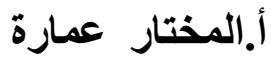

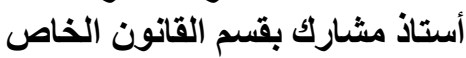

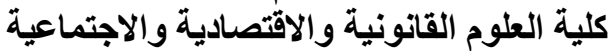 \\ جامعة محمد الخامس ـ الرباط المملكة المغربية
}

رغم تعدد السلع و الخدمات التي تعرضها الأسواق الاستهلاكية، فإن المستهالك لا بمنح حرية الاختيار

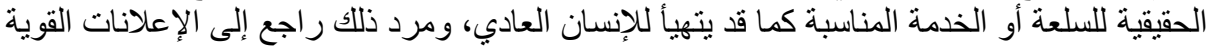

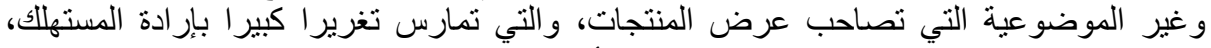

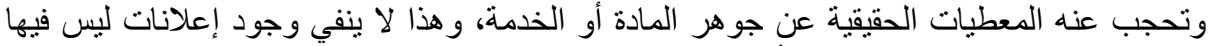

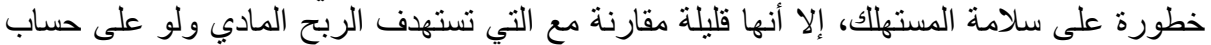
سلامة رضا المستهلك، بل ويتعدى الأمر أحيانا إلى سلامته التصحية.

ولهذا كله، اتجهت مختلف التشريعات المقارنة ومنها المغربي إلى وضع تنظيم قانوني خاص وضاص ومبانثر

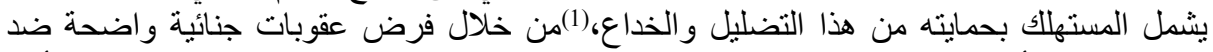

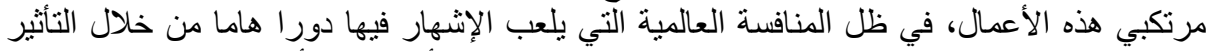

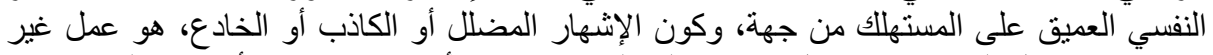

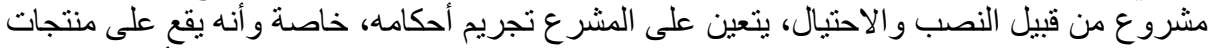

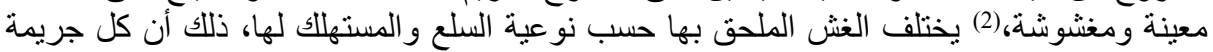

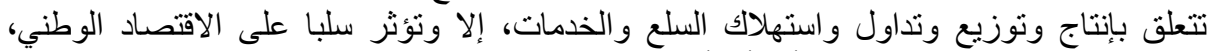

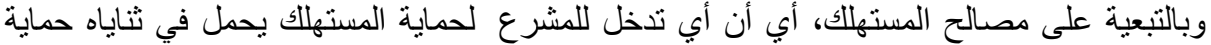
اقتصاد الدولة ومصالحها العليا عموما.

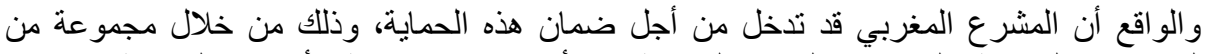

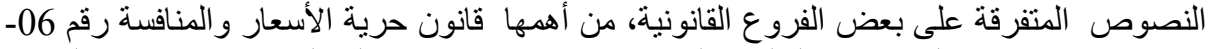
99، وقانون زجر الغش في السلع والبضائع، وقانون 31-08 المتعلق بتحديد ندابير لحماية المستهلك...إلخ. من هنا نجدنا أمام طرح التساؤل عن مدى تحقق حماية جنائية فعلية للمستهلك من الإشهارات

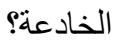

إن الجواب على هذا التساؤل سنخصص لله مبحثين، نحاول من خلال الأول التعريف بمفهوم الإشهار أو الإعلان الاحتيالي وصوره، على أن نفرد الثاني للآليات الجنائية لحماية المستهلك ضحية الإلشهار

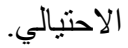

المبحث الأول: ماهية الإشهار التجاري الاحتيالي وصوره

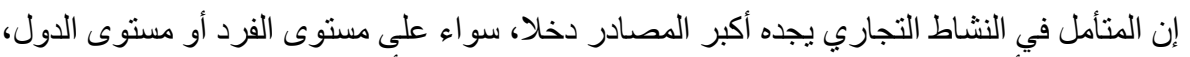

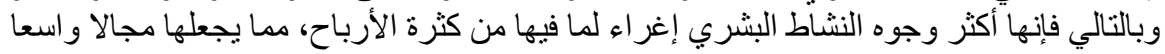
(c) جامعة الإخوة منتوري قسنطينة، الجز ائر 
لاستخدام جميع أنواع الحيل من أجل ترويج السلع و الخدمات، ومن تلك الحيل اللجوء إلى الدعايات

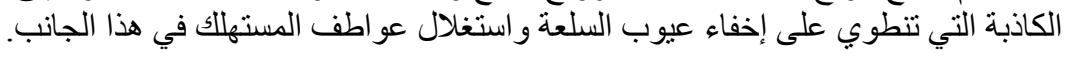

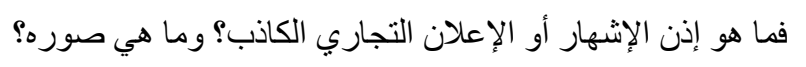

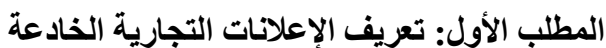

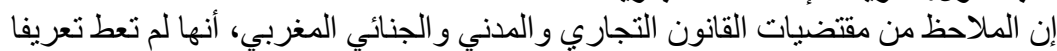

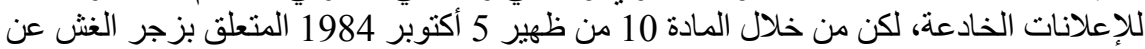

البضائع.

نستخلص أن الإعلان الخادع هو :"من اشتمل مضمونه على ادعاء أو بيان كاذب و عرض الإنه غير مبني

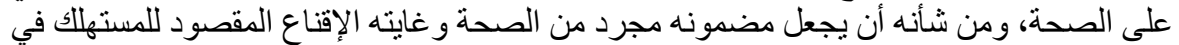
الغلط و إغو ائه بالادعاءات المزيفة وغير الو اقعية".

و وأمام قصور هذا التعريف تولى بعض الفقه هذه المهمة، بحيث عرفه بأنه:

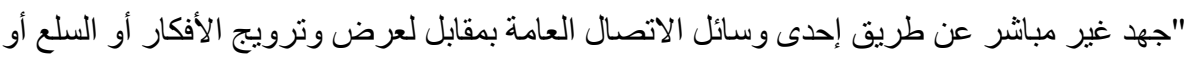

الخدمات يفصح فيها عن الثخص المعلن".

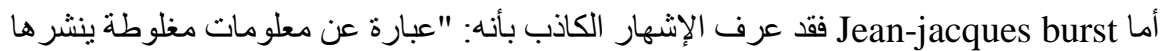

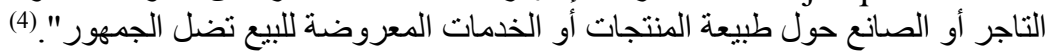

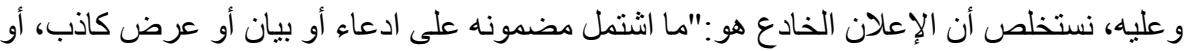

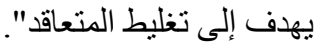

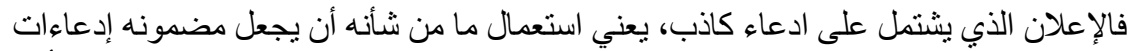

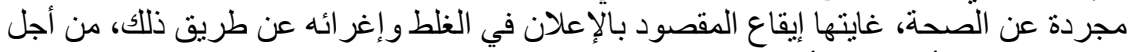
استعمال السلعة أو الخدمة أو اقتنائها.

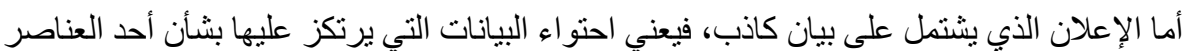

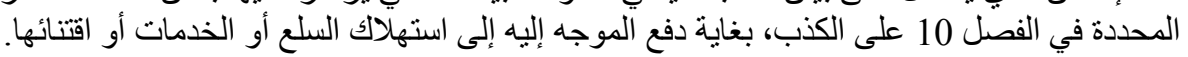

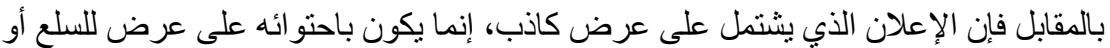

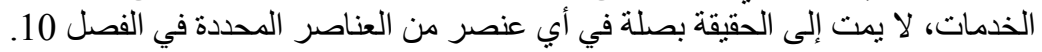

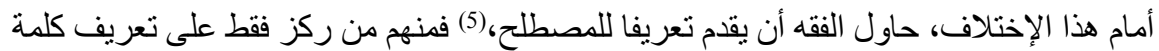
الخداع معتبر ا بأنه:"إلباس أمر من الأمور مظهر يخالف حقيقة ما هو عليه".

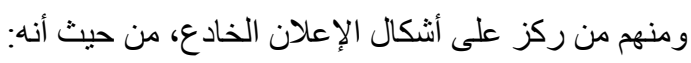

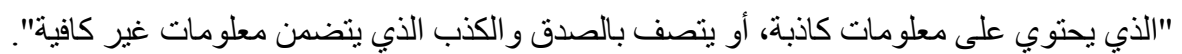

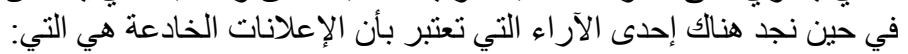

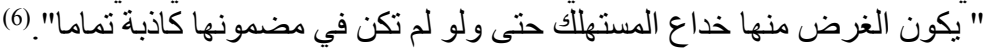

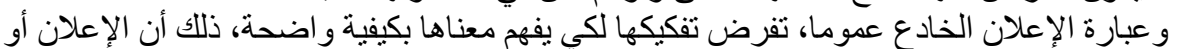

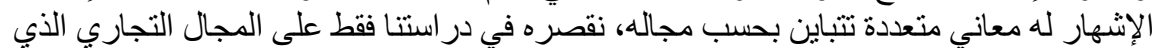




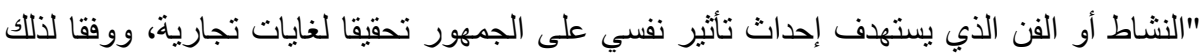

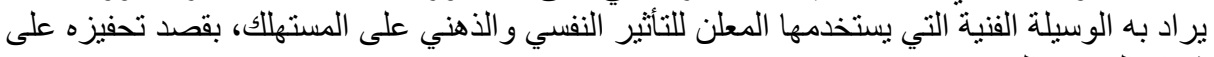

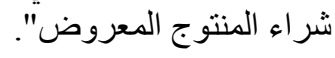

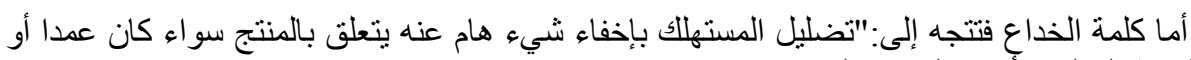
بطريقة الترك، وأيضا الكذب عليه".

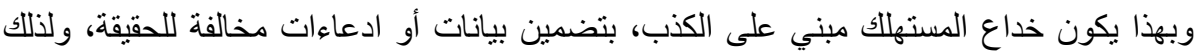

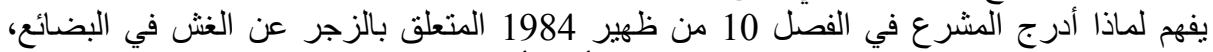

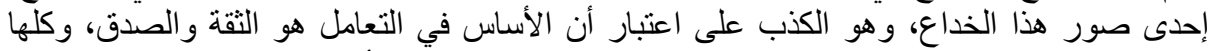
صفات تتنافى مع الكذب، الذي هو ادعاء وز عم مخالف للحقيقة، شرط أن أن يرد كما جاء في في الفصل 10 العناصر المتعلقة بالسلعة أو الخدمة.

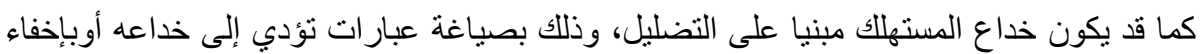

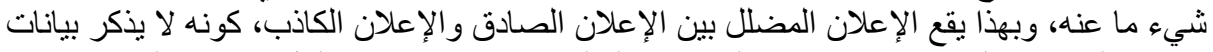

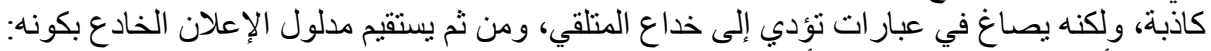

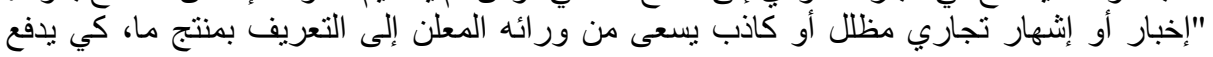

بالمستهرلك إلى اقتنائه".

$$
\text { المطلب الثاني: صور الإثهار ـ الإعلان ـ الكاذب الهب }
$$

إذا كان الإشهار التجاري بشكل عام الوسيلة الأسرع و الأنجع، لكسب ثقة المستهلك من مختلف الفئات

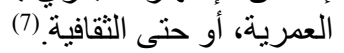

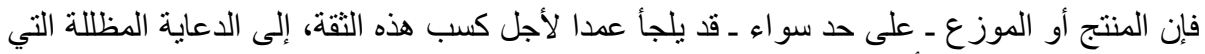

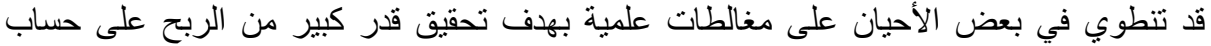
المستهلاك الذي تخدعه هذه الدعاية. (8)

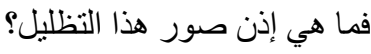

\section{الفقرة الأولى: الغش عن طريق الخداع}

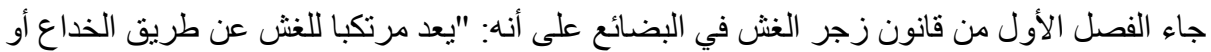

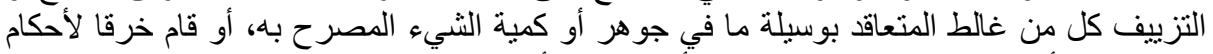

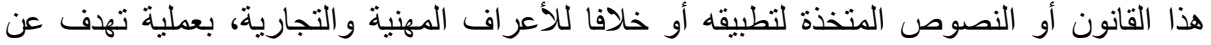
طريق التدليس إلى تغيير ها". (9) النعرصن

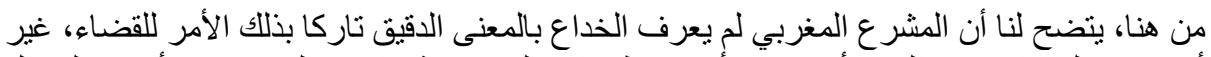

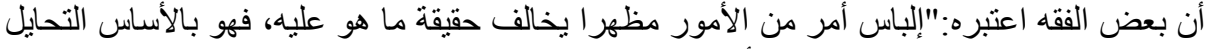

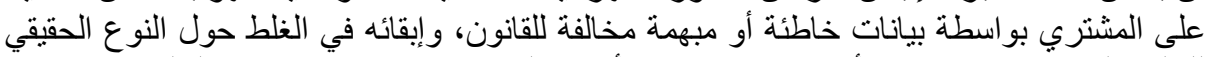

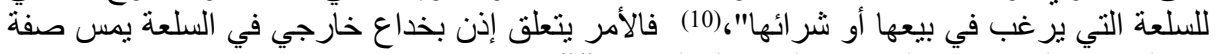

من الصفات التي حددها المشر ع على سلى سبيل الحصر.

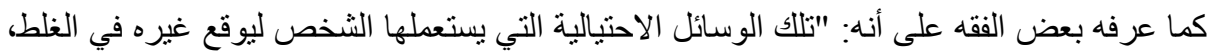

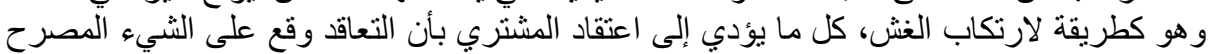
به، أو أن المسلم، هو ما وقعت عليه بنود الُعقد والاتفاق". (12) 
أي أن البائع يمارس أساليب تدفع إلى الاعتقاد بأن الثيء موضوع التعاقد بالرغم من مخالفته للحقيقية مطابق لتلك الحقيقة.

وتقوم جريمة الغش عن طريق الخداع شأنها شأن جميع الجرائم على 3 أركان أساسية(13) وهي الركن

القانوني، و الركن المادي، ثم الركن المعنوي.

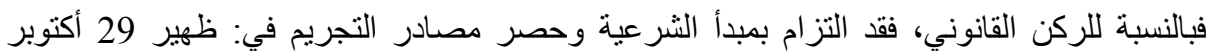

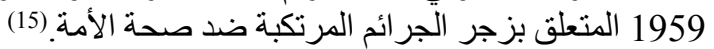

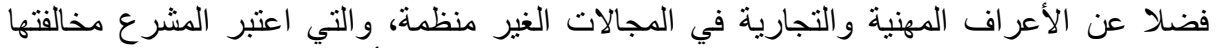

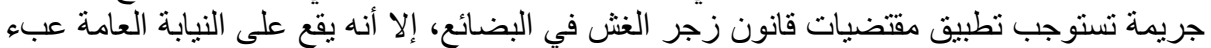

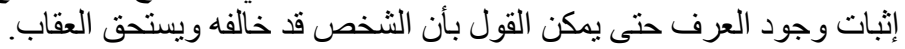

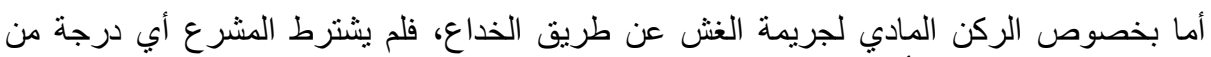
الجسامة، لكون الثقة هي أساس المعاملات التجارية.

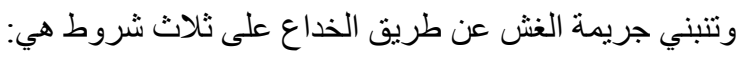

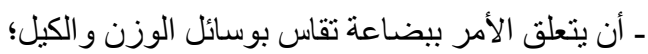

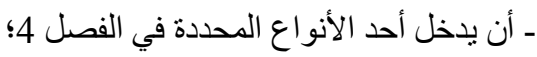

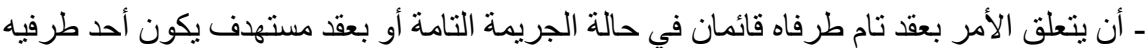

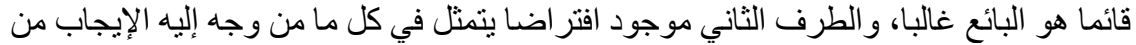

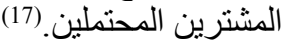

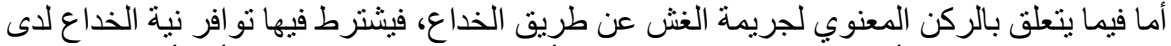

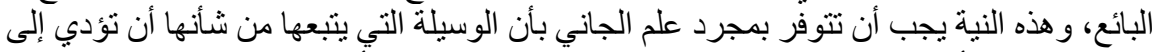

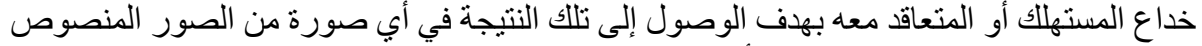

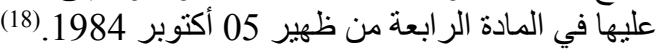

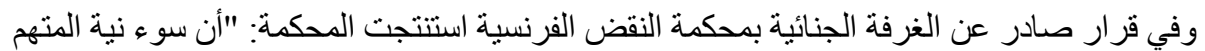

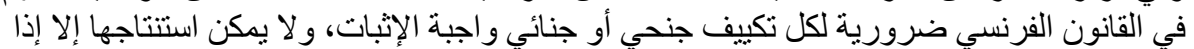

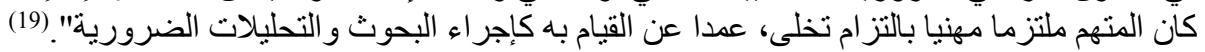

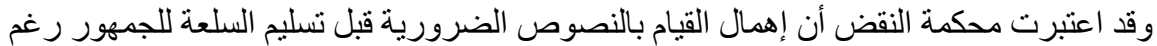

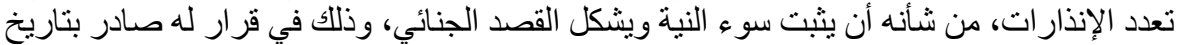
29 مارس 1962 في قضية فانيني فستور . (20)

الفقرة الثانبة: الغش عن طريق التزييف

يقصد بعنصر التزييف تغيير حقيقة البضاعة، تغيير ا من شأنه أن بخفي حقيقتها عن المستهلك سواء أوناء تعلق الأمر بذانتئها وخصائصها الجو هرية أو بتركيبتها، أو محتو الها.

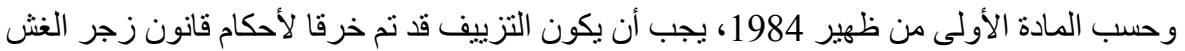

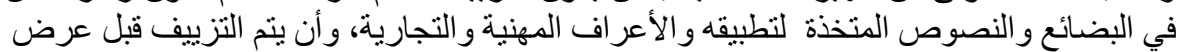

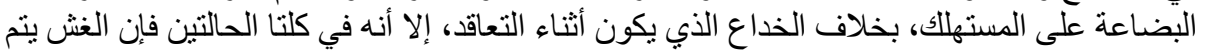
بعملية تعاقدية و اقعية أو محتملة لا تستجيب للمو اصفات القانية التونية المطلوبة. 


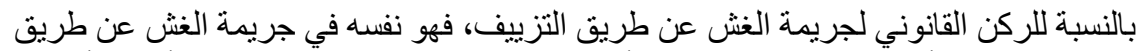

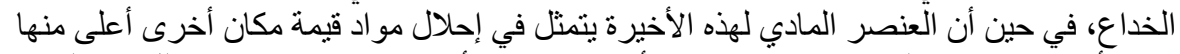

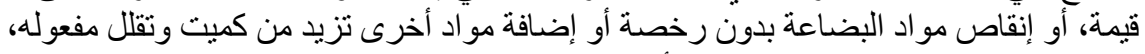

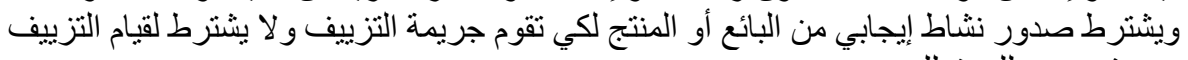
حدوث ضرر للمستهلك.

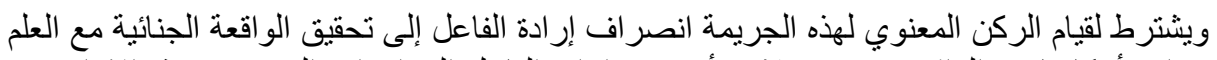

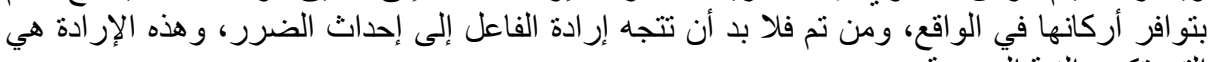
التي تكون النية الجرمية.

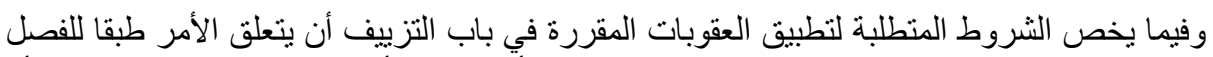

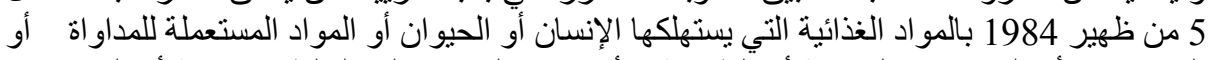

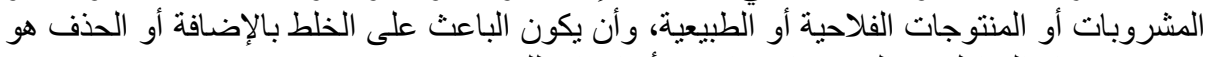

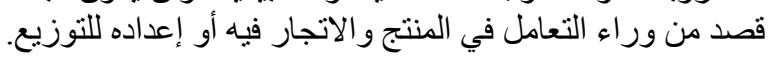

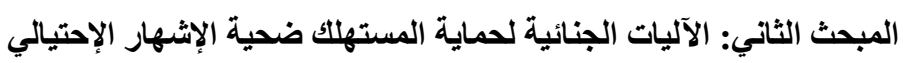

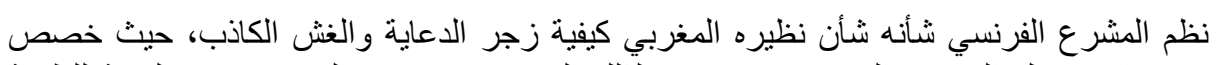

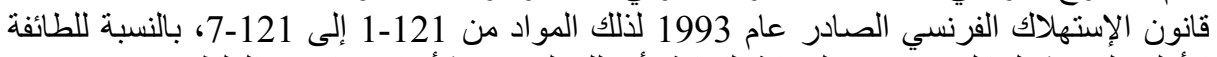
الأولى التي تشمل كل من يقوم بالاعباية الكاذبة، أو تللك التي من شأنها الإيقاع في الغلط.

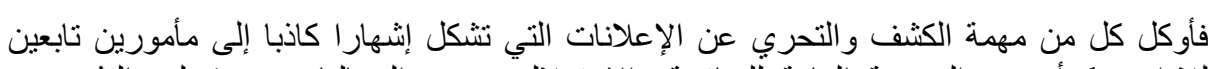

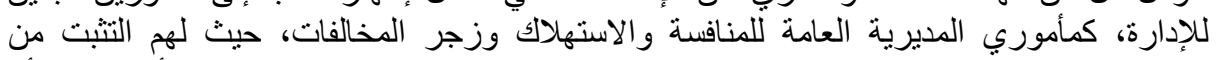

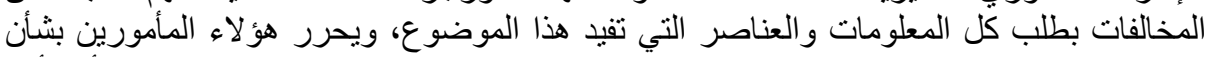

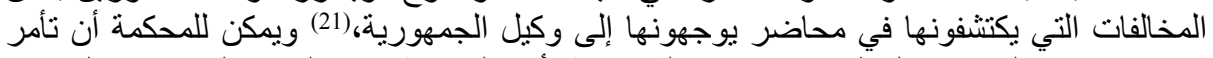

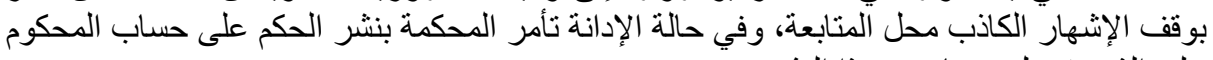
عليه الذي يتحمل مصناريف هذا النشر.

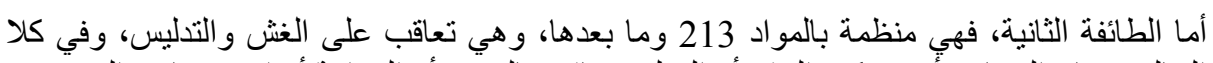

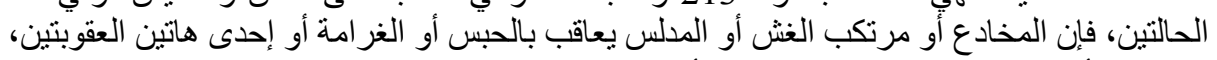
كما يمكن أن تضاف إليهما عقوبات تكميلية أخرى.

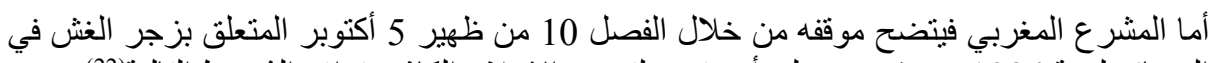

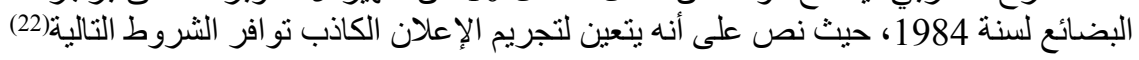

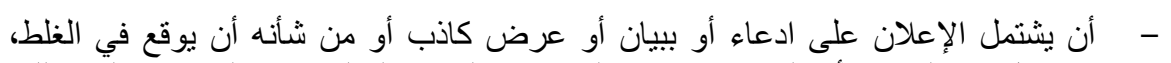

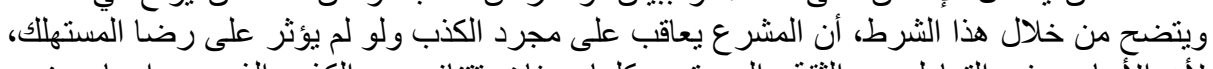

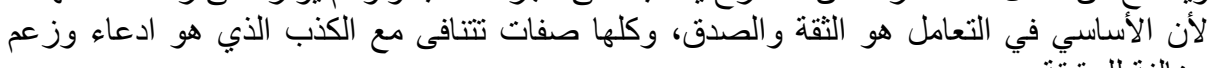

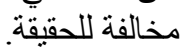

ويستفاد من هذا الثرط أن جميع الوسائل التي من شأنها تضليل المستهلك محرمة. (23)

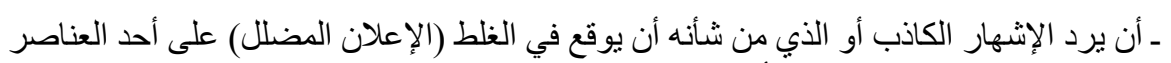

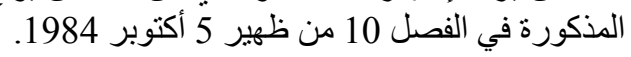

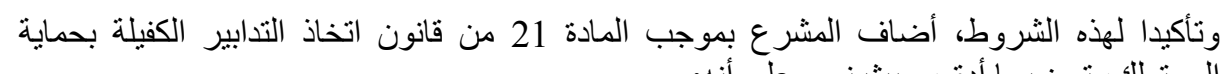
المستهرلك، توضيحا أدق، حيث نص على أنه: 


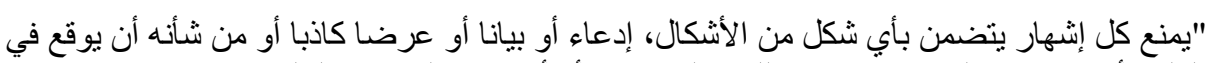

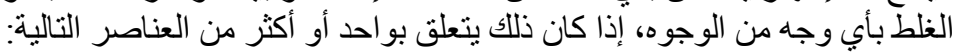

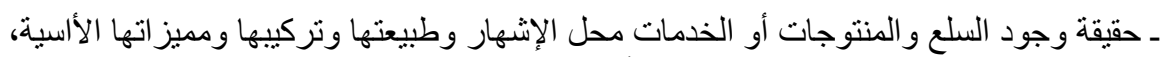

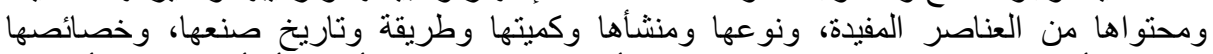

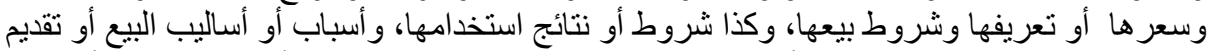

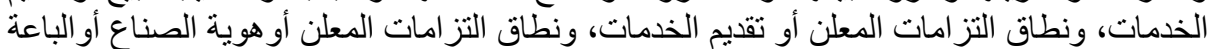
أو المنعشين أو مقدمي الخدمات أو صفتنهم أو مؤهلاتهم".

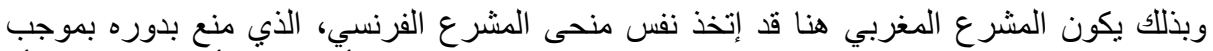

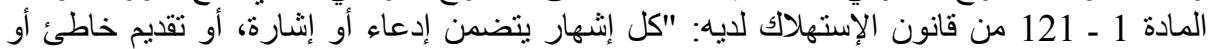

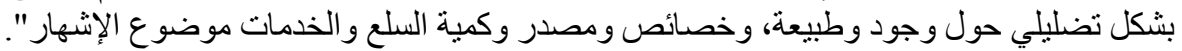

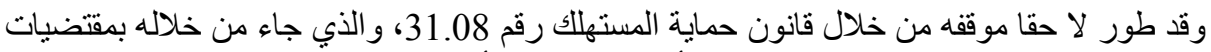

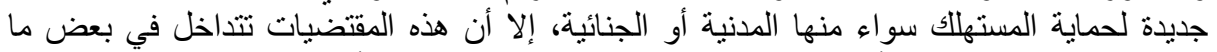

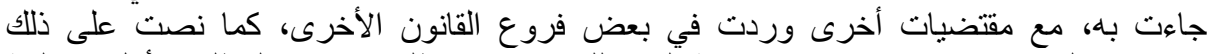

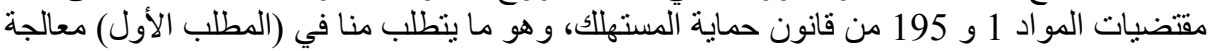

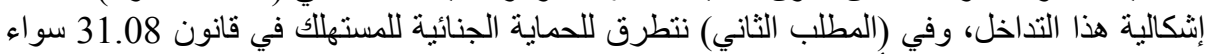
على المسنوى الموضو عي أو الإجر ائي مركزين في ذلك على خصوصياتها.

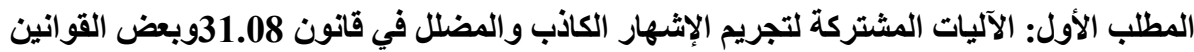

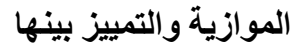

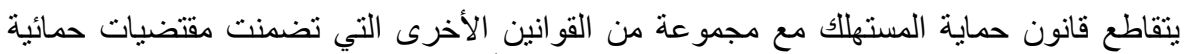

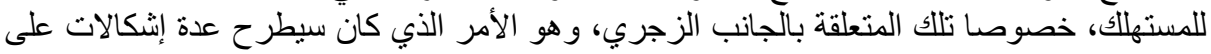

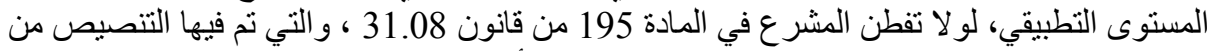

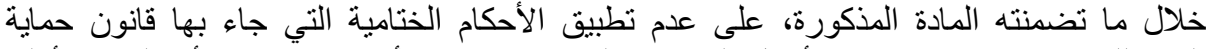

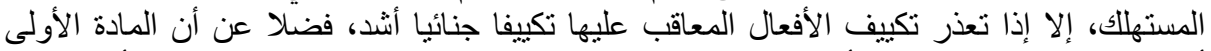

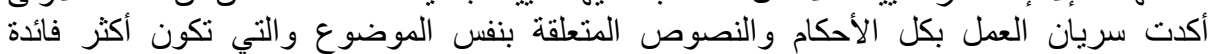

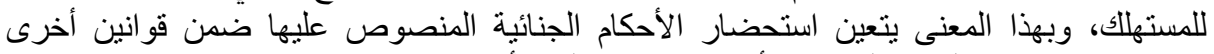

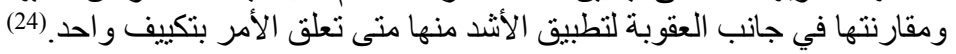

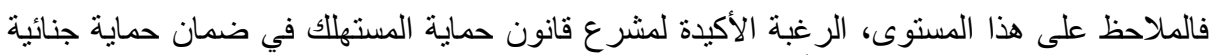

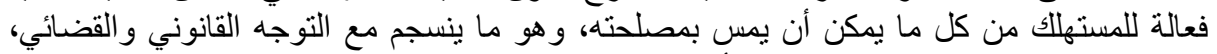

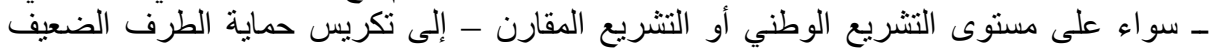
و الذي هو في هذه الحالة المستهلكي.

ذللك أن الحماية الجنائية ييقى لها دور طلادية طلائعي، في ضمان نطبيق المقتضيات الحمائية المنقدمة اللمتنهلك التي جاء بها قانون 31.08.

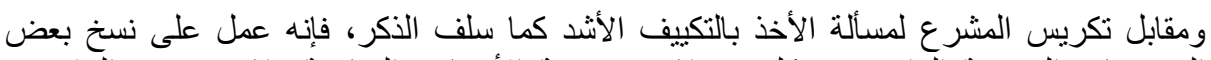

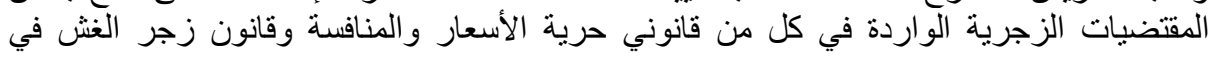
البضائع.

حيث تم نسخ أحكام المادة 10 من قانون زجر الغش في البضائع، و المادتين 49 و و 50 من قانون حرية الأنية

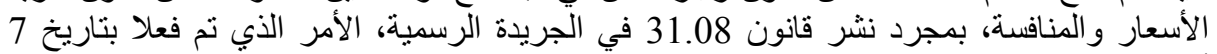


وفي نفس السياق تم نسخ أحكام المو اد 47 و 48 و 48 و 71 من قانون حرية الأسعار والمنافسة بعد نشر الأحكام التنظيمية للمو اد 3 و 4 و و 6 ومن 12 إلى 14.

\section{المطلب الثاني: آليات الزجر الجنائية في القانون 31.08 ومن الفي}

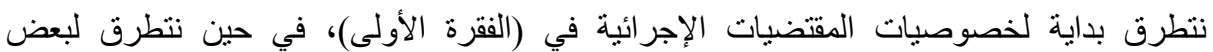
المقتضيات الموضوعية في (الفقرة الثانية).

\section{الفقرة الأولى: المقتضيات الجنائية الإجرائية}

الملاحظ أن هناك مجموعة من الخصوصيات التي تهم المقتضيات الإجرائية التي جاء بهاء التها قانون

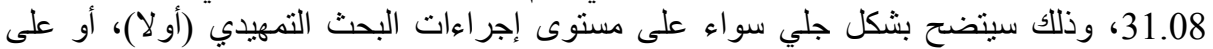
مستوى الضمانات المخولة لصالح المخالفين في انسجام مع ضمانيات الصنات المحاكمة العادلة (ثانيا).

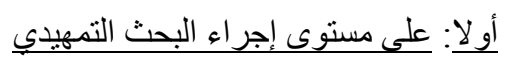

تتضح تلك الخصوصيات المتعلقة بإجر اءات البحث التمهيدي من خلال ما يلي:

* - م الضابطة القضائية المختصنة:

قد خولت مقتضبات قانون حماية المستهلاك الصفة الضبطية لـ:

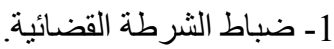

2- باحثون منتدبون خصيصا لهذا الغرض من قبل الإدارة المختصة و الذين يثرط فيهم(25)

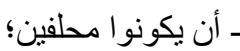
ـ أن يكونو ا حاملي لبطاقة تسلم من الإدارة المختصة وفقا لنص تنظيمي؛

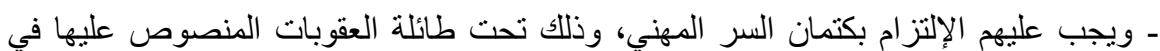
الفصل 446 من القانون الجنائي.

\section{* * *لى مستوى محاضر البحث:}

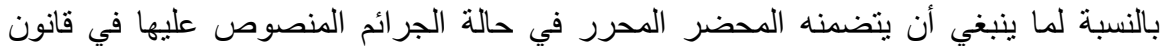

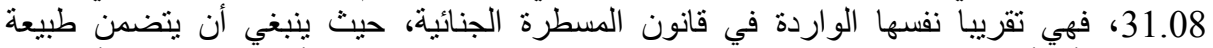

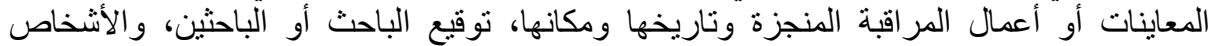

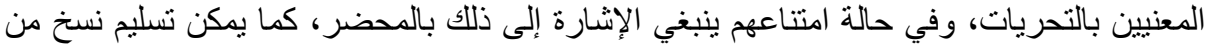

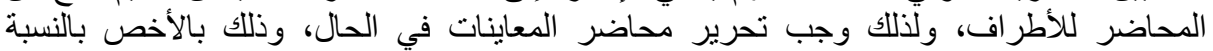

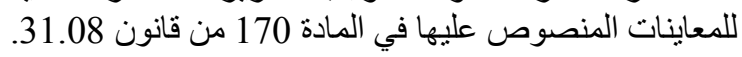

أما فيما يتعلق بنوجيه المحاضر، فينبغي أن يتم خلال 15 يوما من إتمام البحث، حيث يتعين إحالتها

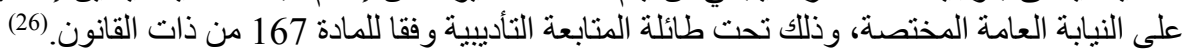

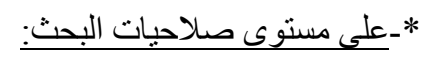

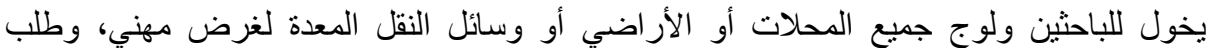

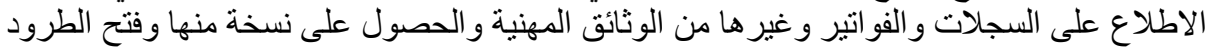

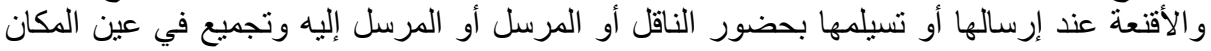


كما يمكن لهم طلب، تعيين خبير قضائي لإجر اء أية خبرة حضورية لازمة، وذللك طبقا للمادة 169 من

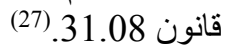

ثانيا: الضمانات الممنوحة للمخالفين

يجب على الباحث أن يقبد الإستدعاء الموجه للمخالف في سجل خاص، يشار فيه إلى تاريخ نسليم

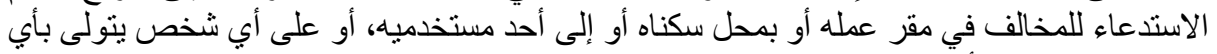

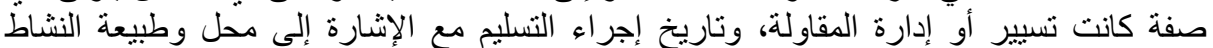

الممارس.

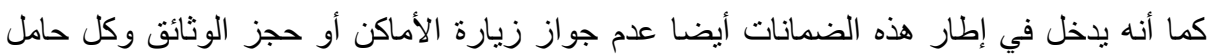

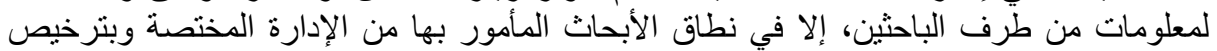

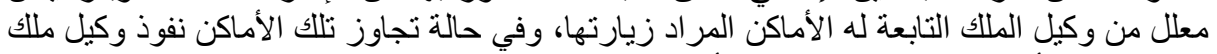

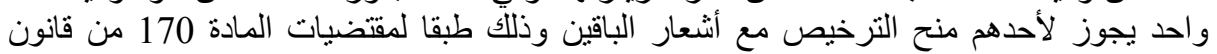

أضف إلى ذلك، أن الزيارة والحجز تتم بمراقبة وكيل الملك وبحضور ضابط الثرطة القضائية،

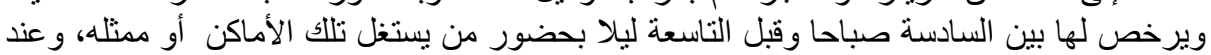
غيابه تطبق أحكام المادة 104 من قانون المبادئ المسطرة الجنائية.

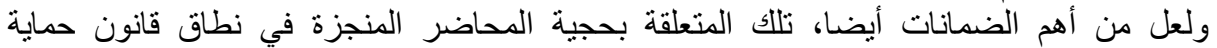
المستهلاك، حيث أن هذه الأخيرة يوثق بمضمونها إلى أن يثبت العكس بأَية وسيلة من وسائل

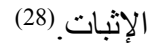

الفقرة الثانية: الجرائم وعقوباتها في إطار قانون

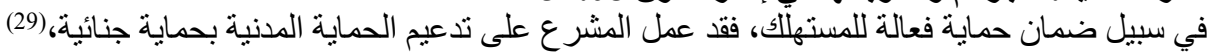

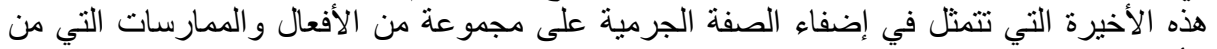

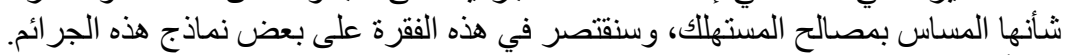
أولا - الإشهار المظلل:

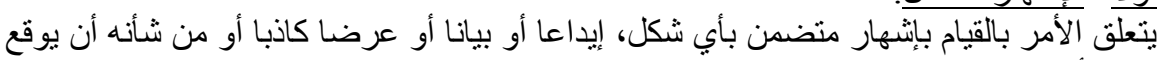

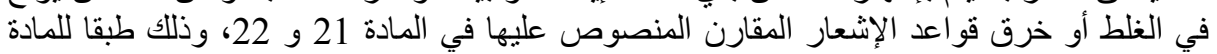

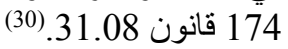

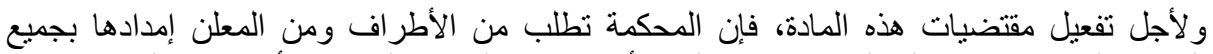

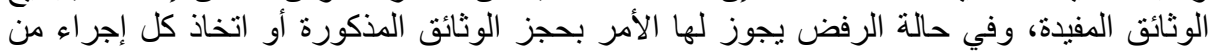

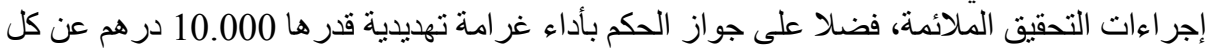

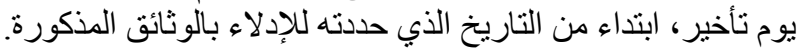

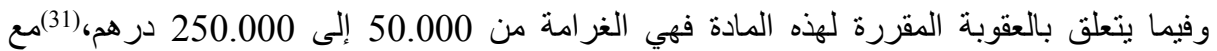
إمكانية رفع المبلغ الأقصى للغر امة إلى نصف نفقات لفات الإثهار المكون للجنحة، حسب المادة 174، هذا إذا كان المخالف شخصا طبيعيا.

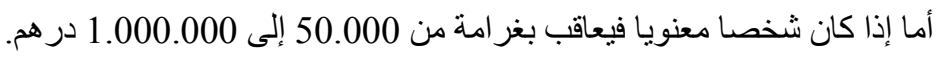

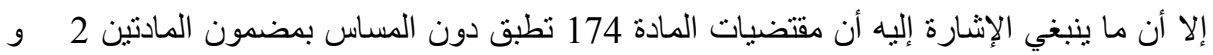
67 من القانون رقم الإنارة 77.03 المتعلق بالإنشهار السمعي والبـان البصري.

ثانيا ـ استغلال ضعف أو جهل المستهلك نثأ عنه التزام: 
فقد نصت المادة 184 من قانون 31.08 على المعاقبة على مخالفة أحكام المادة 59، و المتعلقة باستغلال ضعف المستهللك، هذه الأخيرة التي نصن فن على أنه أنه: "يقع باطلا بقوة القانون كل التزام نشأ بفعل استغلال ضعف أو جهل المستهلك مع حفظ حقه في

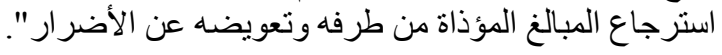

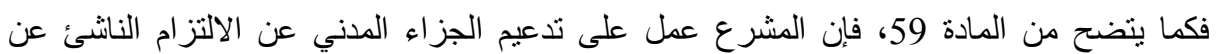

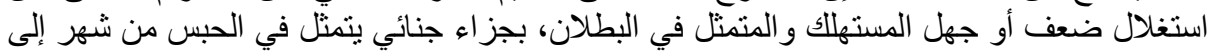

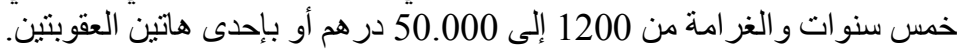

و إذا كان المخالف شخصا معنويا فالعقوبة تكون ما بين 5400.000 در هم و 1.000 .000 درهم، كل ذلك الكي

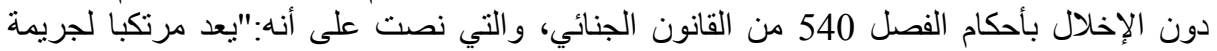

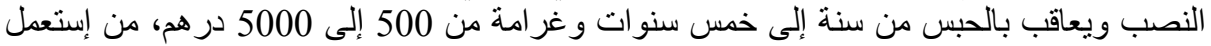

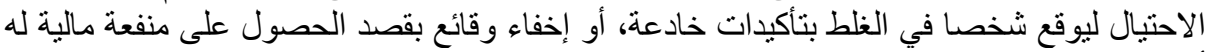
أو لشخص آخر.

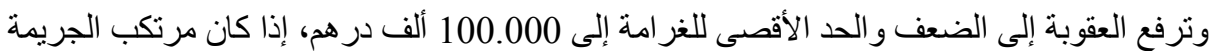

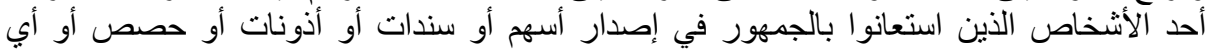

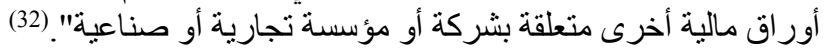

خاتمة: ملإن

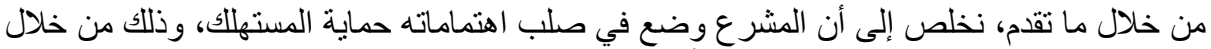
تدعيمه للحماية المدنية سو اء منها القانونية أو القضائية، بحماية جنائية تتفرق على مجموعة من فئه فروع القانون.

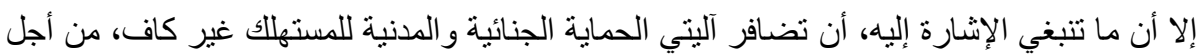

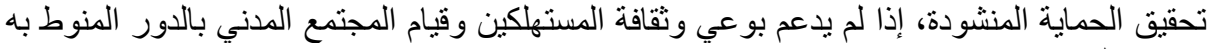
في هذا الصدد.

\section{الكهو (مش:}

1- للتوسع حول هذه الحماية:

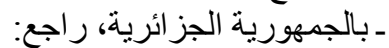
حليمة بن شعاعة: الحماية الجزائية للمستهلك في التشريع الجزئة ائري، رسائة رسالة لنيل الماستر في الحقوق،

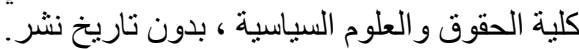

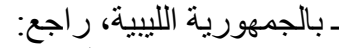

إدريس سعود محمد الغويج: الحماية الجنائية الإجر ائية للمستهلك في القانون الليبي، أطروحة دكتور اه في

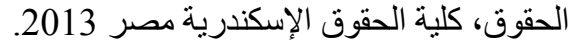

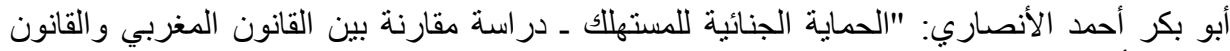
الليبي"، أطروحة دكنور أه في القانون الخاص، كلية الحقوق جامعة الحسن الثاني عين الثق الثن 1997.

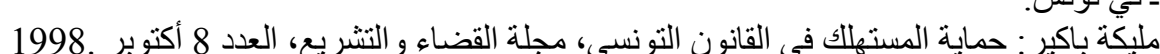

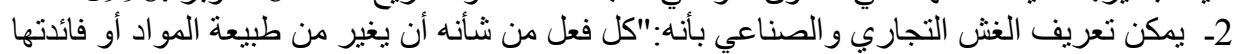

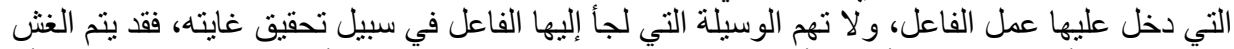

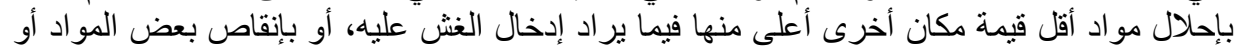


إضافة مو اد أخرى عليه تزيد من كميته وتقلل من مفعوله، وغير ذلك من الصور التي لا تدخل تحت

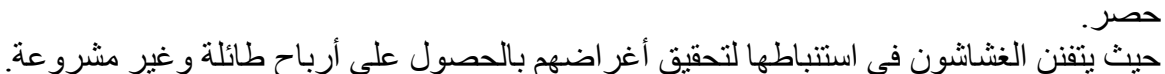

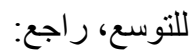
سميحة القليوبي: غش الأغذية وحماية المستهلك، بحث مقام لمؤتمر حماية المستهلك، القاهرة مارس

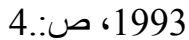
3 - حسن فتحي:"حدود مشروعية الإعلانات لحماية التاجر و المستهلك"، بدون تاريخ نشر أو طبعة، ص

4 - Brust Jean-Jacques, kouvar robert «droit de la concurrencée, éd. Economica, Paris 1981. P: 175

$$
\text { 6- 5- عبد المنعم موسى إبر اهيم، مرجع سابق الإثارة إليه. }
$$

سمير العكرون: الإشهار التجاري وحماية المستهلك، مجلة القضاء والتشريع، العدد 8، أكتوبر 2008،

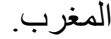
7ـ ونقصد هنا الدعاية التجارية، وهي صورة من صور الإعلان التجاري الذي يصل فيه المعلن إلى الى أقصر الحدود في ترويج وتسويق الإنية السلع، و الخدمات.

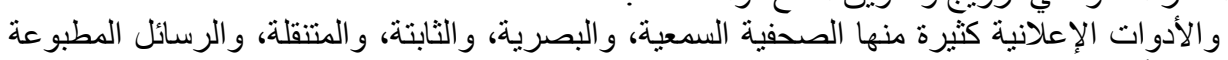

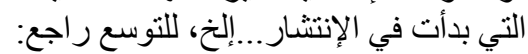

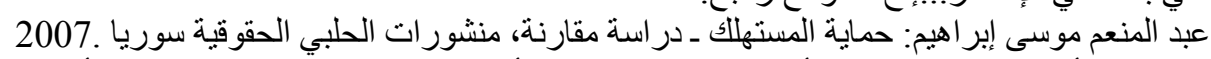

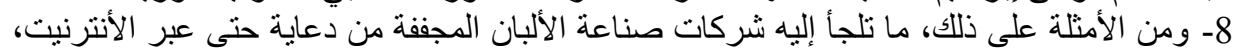

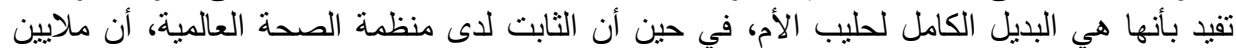

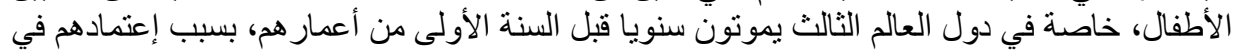

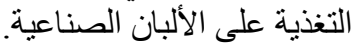

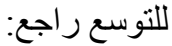

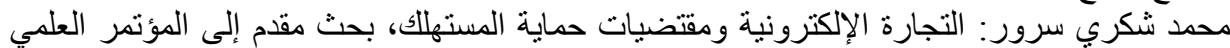
لأكاديمية شرطة دبي ـ الإمارات العربية المتحدة، 27/26 فبر اير الإن 2003، ص:6.

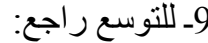
فاتح كمال : الحماية الجنائية للمستهلاك في إطار القانون المتعلق بالزجر عن الغش في البضائع، مجلة

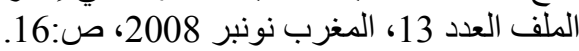
10ـ محمد بوفادي: "حماية المسنهلك على ضوء صنو قانون زجر الغش في البضائع" مجلة المحكمة العدد 1، .2003 11- دليل القانون الجنائي المغربي، سلسلة الدلائل و الثروح - منشورات المعهذ الوطني للادراسات القضائية - وزارة العدل صفحة الفيل 217-218. 12- -جو اد الغماري: "جرائم الغش في البضائع"، مطبعة النجاح الجديدة، الدار البيضاء، الطبعة الثانية 2002، ص 101

13 - http://www.targuistcity.net/vb/shawthread.php ?t=5057\&page=1 (vu le26/11/2011)16h55. 


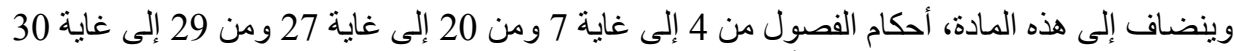

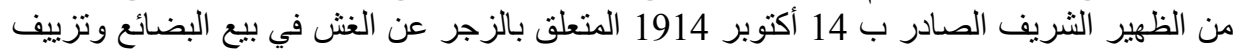

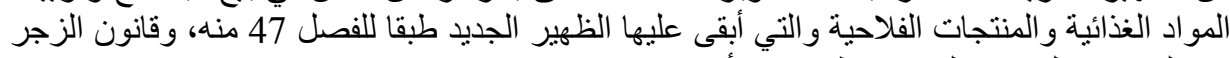

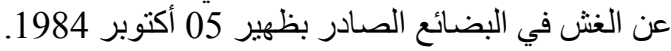

16 ـ هشومة غازي: الحماية الجنائية للمستهلك على ضو الئر القانون، رسالة لنيل دبلوم الماستر في القانون

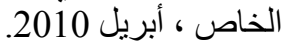

17- في جميع الأحو ال، فإن الركن المادي في جريمة الغش، يتحقق بأي فعل من الأفعال التالية:

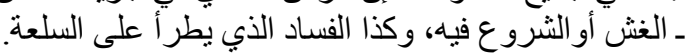

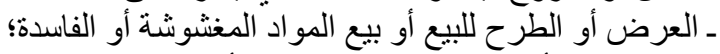

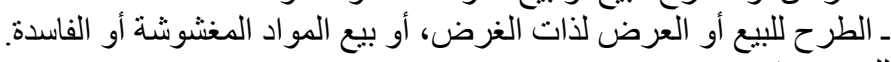

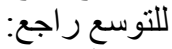

عبد الله حسن محمود: حماية المستهلك من الغش التجاري والصناعي، دار النهضة العربية، القاهرة مصر، 2002.

18- الصادر بتنفيذ الظهير رقم 1.83 .108 بتاريخ 9 محرم 1405 (5 أكتوبر 1984) منشور بالجريدة

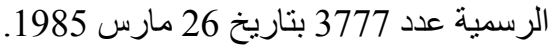

19- قرار صادر بتاريخ 02 أكتوبر 1973 - المجلة المغربية للقانون عدد 11 سنة 1987 - فبراير -

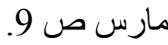

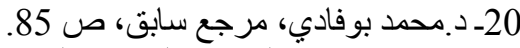

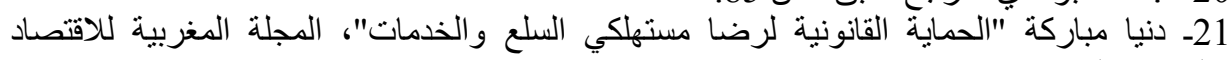

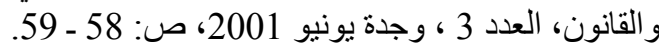

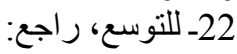

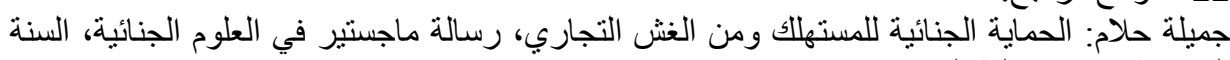
الجامعية 2011، كلية الحقوق مر اكث.

23ـ لمزيد من التفاصبيل راجع ظهير 5 أكتوبر 1984.

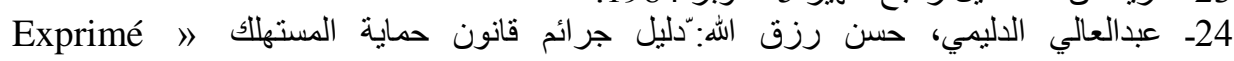

impression

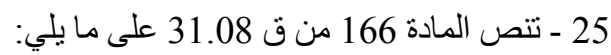

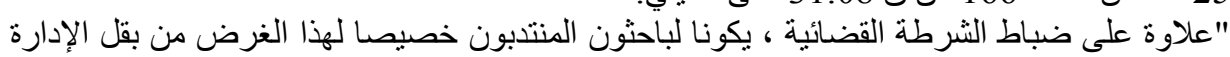

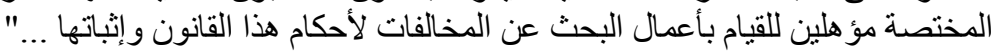

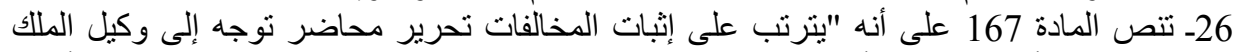

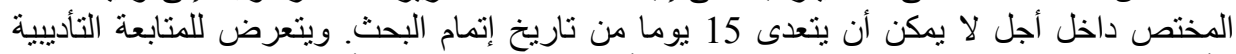

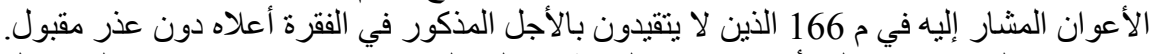

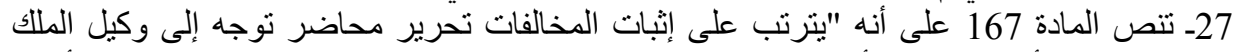

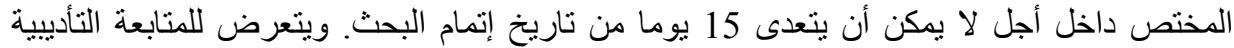

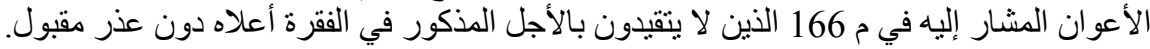

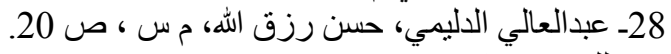

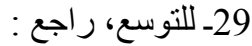

محمد العروصي: الحماية الجنائية من الإعلانات التجارية الخادعة, المجلة المغربية لقانون الأعمال و المقاو لات, عدد 7 الرباط يناير 2005 30ـ تتص المادة 174 "يعاقب بغر امة من 22 بـ 50.000 إلى 250.000 درهم على مخالفات أحكام المادتين "...22, 21 


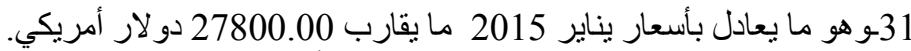

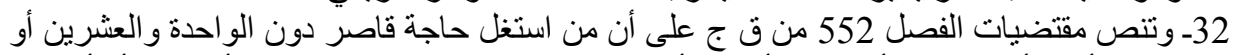

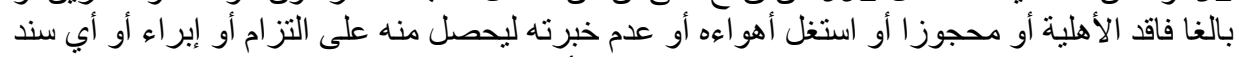

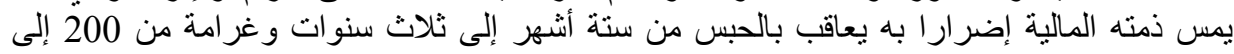
وإذا كان الجم. و إذا كان المجني عليه تحت سلطة الجاني أو تحت إثر افه أو تحت رعايته رفعت العقوبة إلى الحبس من سنة إلى خمس سنو ات و الغر امة من 250 إلى الى 3000 در هم. 